\title{
A Defense of Holistic Representationalism JACOB BERGER
}

\author{
Mind \& Language 33(2): 161-176.
}

(Please quote the published version.)

\begin{abstract}
Representationalism holds that a perceptual experience's qualitative character is identical with certain of its representational properties. To date, most representationalists endorse atomistic theories of perceptual content, according to which an experience's content, and thus character, does not depend on its relations to other experiences. David Rosenthal, by contrast, proposes a view that is naturally construed as a version of representationalism on which experiences' relations to one another determine their contents and characters. I offer here a new defense of this holistic representationalism, arguing that some objections to atomistic views are best interpreted as supporting it.
\end{abstract}

\section{Introduction}

Perhaps the most promising theory of the qualitative character of perceptual experience is representationalism, the view that an experience's character is identical with certain of its

\footnotetext{
I thank Mazviita Chirimuuta, Will Davies, Michael Devitt, Peter Fazekas, Craig French, Jon Golin, Angelica Kaufmann, Hasen Khudairi, Uriah Kriegel, John Morrison, Myrto Mylopoulos, Stephen Neale, Adam Pautz, David Pereploytchik, Ben Phillips, Jake Quilty-Dunn, Tony Ro, Susanna Schellenberg, Daniel Shargel, Joshua Shepherd, Jens van ‘t Klooster, and Nick Young for their comments on and discussions of aspects of this material. Versions of this paper were presented at Tony Ro’s cognitive neuroscience lab, Jesse Prinz's Spring 2013 course at NYU, Bryn Mawr College, and the Tilburg Mind and Cognition workshop—and I thank the audiences there for their useful discussion. I especially thank Bence Nanay, Jesse Prinz, and David Rosenthal for their extremely helpful discussions regarding these topics.
}

Address for correspondence: Department of English and Philosophy, Idaho State University, 921 South 8th Avenue, Stop 8056, Pocatello, ID 83209-8056, USA.

Email: jfberger@gmail.com 
representational properties (e.g., Harman, 1990; Dretske, 1995; Tye, 1995; Lycan, 1996; Hill, 2009). ${ }^{1}$ Although there are many varieties of representationalism (for a taxonomy, see Chalmers, 2010, chapter 11), standard versions hold that the reddish character of a visual experience of a strawberry consists in its suitably representing the color red. Representationalism is attractive for many reasons, ${ }^{2}$ not the least of which is that, if we can provide a naturalistic account of perceptual representation, it seems that we can thereby naturalize qualitative character (e.g., Kriegel, 2009, p. 59; Cutter and Tye, 2011, p. 90).

To date, most representationalists—notably Fred Dretske (1995) and Michael Tye (1995; 2000) - have attempted to naturalize perceptual representation by endorsing what are often called 'tracking theories' of perceptual content (see also, e.g., Lycan, 1996; Hill, 2009; Cutter and Tye, 2011). Such views hold that a perceptual experience represents a perceptible property—such as a color, odor, or sound-just in case it stands in the appropriate tracking relation to it; candidates include detecting, carrying information about, or causally co-varying under optimal conditions with the property (for a review, see Neander, 2006). Such theories seek to be naturalistic insofar as the relevant content-determining tracking relations and perceptible properties purportedly can be characterized in wholly mind-independent physical terms. Tye (2000), for example, endorses a version of color physicalism, according to which perceptible colors are identified with (sets of) surface spectral-reflectance properties ('SSRs') (for an independent defense of color physicalism, see, e.g.,

\footnotetext{
${ }^{1}$ Representationalism often goes by other names, such as 'representationism' and 'intentionalism'.

2 There are many arguments for representationalism (see, e.g., Harman, 1990; Tye, 1995; Kriegel, 2009; Pautz, 2010). Of

course, not everyone is drawn to the view: qualia realists typically maintain that qualitative character is nonrepresentational and irreducible (e.g., Block, 1995); nä̈ve realists maintain that qualitative character is explained relationally, not representationally (see, e.g., the essays in Brogaard, 2014). As we shall see, my goal here is not to defend representationalism per se, but to provide arguments for a particular version of it, presuming that representationalism in general is attractive.
} 
Byrne and Hilbert, 2003). It is standard to call versions of representationalism that depend on such theories of content varieties of 'tracking representationalism' (for a survey of such views, see, e.g., Bourget and Mendelovici, 2014).

Crucially, varieties of tracking representationalism are atomistic insofar as they hold that a perceptual experience's content, and therefore qualitative character, depends only on the experience's standing in the right kind of one-to-one relation to the relevant perceptible property; it does not depend on its relations to other kinds of perceptual experiences. It is consistent with tracking representationalism, for example, that a creature be capable of visually experiencing one color only.

By contrast, several theorists—such as Wilfrid Sellars (1963), Sydney Shoemaker (1982; 1994), Austen Clark (1993; 2000), and Paul Churchland (2007)—have proposed that we understand the qualitative character of perceptual experiences in a holistic way in terms of experiences' relationships to one another. On this kind of view, in order for a creature to visually experience a particular color, the creature must be able to visually experience a host of colors. I focus here on David Rosenthal's $(1991 ; 2005 ; 2010 ; 2012)$ version of the view, as I believe it is the most detailed and promising version of the approach. Although Rosenthal does not explicitly defend it as such, I maintain that his view can be naturally construed as holding a version of representationalism that invokes a holistic theory of perceptual content.

My goal here is to provide a new defense of this kind of holistic representationalism. My arguments emerge from exploring Adam Pautz's (2006; 2010; 2014) critique of tracking representationalism. Rather than rejecting representationalism, Pautz endorses the nonnaturalistic view that perceptual representation is primitive (cf. Chalmers, 2010). Insofar as Pautz regards perceptual representation as primitive, he denies that relations among experiences determine their contents_-and so his view is, like tracking representationalism, atomistic. But giving up tracking 
representationalism's goal of naturalizing perceptual content and qualitative character is unappealing and unnecessary. I argue that Pautz's considerations are best interpreted as supporting a naturalistic version of holistic representationalism that is preferable to atomist alternatives. After discussing varieties of representationalism in section 2, I describe this holistic alternative in detail in section 3. In section 4, I present two of Pautz's challenges to tracking representationalism, which may be construed as arguments for holistic representationalism. I close by addressing some objections to this holistic view in section 5 .

\section{Varieties of Representationalism}

To understand the debate between atomistic and holistic varieties of representationalism, it is helpful to distinguish it from a related debate. Although representationalists explain qualitative character in terms of representation, many have observed that perceptual representation can and often does occur in the absence of consciousness, as in experiments involving masked priming or pathological conditions such as blindsight (see respectively Kouider and Dehaene, 2007; Weiskrantz, 1997; for representationalist discussion, see, e.g., Tye, 2000, 62-63). Consequently, we must distinguish two questions about the nature of perceptual experience. On the one hand, there is what, following Pautz (2010, p. 333), we can call 'the general question': What explains why a perceptual representation is conscious, as opposed to subliminal? But since perceptual representations with different qualitative characters can all occur consciously, we must distinguish the general question from what Pautz calls 'the quality question': What explains why an experience exhibits its particular qualitative character?

To answer the general question, representationalists must offer a theory of consciousness. And there are a variety of such theories. According to Rosenthal's (1991; 2005) higher-order thought 
theory, for example, a mental state is conscious just in case one has a suitable higher-order thought about it. Tye (2000), by contrast, holds that a perceptual representation is conscious just in case it is suitably poised for impact on cognition. I remain neutral here among answers to the general question, as my interest regards how versions of representationalism differ regarding the nature of perceptual representation— that is, regarding the quality question.

Although they agree that perceptual representation is atomistic, tracking representationalists nonetheless disagree about how to characterize the appropriate content-determining relation. Here Tye characterizes one prominent account: 'For each [perceptual] state S of object x, within the relevant set of alternative states of $\mathrm{x}: \mathrm{S}$ represents that $\mathrm{P}=\mathrm{If}$ optimal conditions obtain, $\mathrm{S}$ would be tokened in $\mathrm{x}$ if and only if and because P' (1995, p. 101). On this view, one's visual experience represents a thing as red in virtue of the fact that one tokens that experience, under optimal conditions, just in case red is present and because red is present. Similarly, Dretske characterizes perceptual representation in terms of what a perceptual state has the function of indicating (as determined by natural selection). Again, such views are atomistic insofar as a perceptual experience's content is not determined by its relations to other perceptual experiences. ${ }^{3}$

Tracking theories of perceptual content thereby echo atomistic theories of the contents of cognitive states such as beliefs or desires. As is well known, there was much debate in the 1980's regarding how to naturalize the contents of thoughts — and two broad approaches emerged. On the one hand, many philosophers developed atomistic theories such as causal-covariational theories (e.g.,

\footnotetext{
${ }^{3}$ Dretske's view may seem holistic insofar as he understands a state's indicator function in terms of how that state is used by the system of which it is a part—by its impact on downstream cognition and behavior-and so the function is determined by the state's relations to other states. But Dretske's view remains atomistic in the relevant sense because a perceptual state's content is not determined by its relations to other perceptual states. It is consistent with Dretske's view that a creature be able to experience one color only, though it may need to be able to be in other cognitive states.
} 
Dretske, 1981), telosemantics (e.g., Papineau, 1984), and asymmetric-dependence theory (e.g., Fodor, 1987). The details of such views do not matter for present purposes; what matters is that, schematically, such views are atomistic insofar as they hold that a cognitive state's content is determined not by its relations to other cognitive states, but by its standing in an appropriate connection to a feature of the world. According to a crude causal theory, for example, for a belief to involve the concept STRAWBERRY is roughly for the belief to causally covary suitably with strawberries.

Others proposed holistic accounts such as inferential- or conceptual-role semantics ('CRS') (e.g., Sellars, 1963; Block, 1986; Harman, 1987). On these views, a thought's content is at least in part determined by its causal or inferential relations to other thoughts (and, on so-called long-arm versions, its connections to the environment and behavior). Central to holist theories is that a mental states' contents depend on those states' relations to one another.

For reasons that are not entirely clear, there has not yet been an explicit parallel debate between atomistic and holistic accounts of perceptual content. Most philosophers of perception seem to simply import a version of atomism about the contents of cognitive states to explain the contents of perceptual experiences. Perhaps perceptual atomism is assumed because holistic theories of cognitive content such as CRS seem to face insuperable difficulties (see, e.g., Fodor and Lepore, 1992). Whether or not these difficulties undermine views such as CRS, I remain neutral regarding which theory best explains the contents of thoughts.

Whatever theory of content applies to thoughts, it is doubtful that this theory would ground perceptual content (see, e.g., Cutter and Tye, 2011, p. 106, fn. 3). Although some philosophers have urged that perceptual experiences and beliefs have the same kind of content (e.g., McDowell, 1994), perhaps the most natural explanation of how perceptual representation differs from representation via thought is that there is a difference in the nature or format of their contents. Thus most representationalists, such as Dretske and Tye, distinguish between the conceptual content of cognitive 
states and the nonconceptual content of perceptual states-however that distinction is drawn (for discussion, see Byrne, 2005). And if perceptual and cognitive content differ in their fundamental nature, it is reasonable to expect that different theories of the grounds of those contents would apply to them.

But even if perceptual content is nonconceptual, it is far from clear that it is grounded via tracking relations. Indeed, tracking theories of perceptual content have recently faced much criticism by Pautz and others (e.g., Mendolovici, 2013; McLaughlin, 2016). But before exploring reasons to reject tracking theories — and thus versions of representationalism that depend on them-I sketch in the next section a holistic variety of representationalism that invokes a theory of perceptual content different from any theory of conceptual content, holistic or otherwise, currently available.

\section{Holistic Representationalism Introduced 4}

Over the years, Rosenthal has developed a sophisticated holistic account of qualitative character, which he calls 'Quality-Space Theory'. ${ }^{5}$ Quality-Space Theory pursues an approach fundamental to cognitive science — a particular set of observable behavioral data form a body of evidence supporting an account of the inner psychological processes that underwrite those behaviors. Here the behaviors in question are a creature's perceptual discriminatory behaviors. Common sense holds that each sensory

\footnotetext{
4 Some of this section borrows from my (2015, section 3).

${ }_{5}^{5}$ Though I focus on Rosenthal's version of holism about qualitative character, there are many varieties of this kind of view. For example, not all proponents agree about this sort of view's scope. Rosenthal maintains, while Clark denies, that such an account extends to the character of perception of spatial properties such as shape. For reasons of space, however, I cannot explore related views or differences between varieties of holism. But much of what I say may be modulated depending on one's preferred version.
} 
modality—such as vision, smell, or taste—enables us to perceptually distinguish among circumscribed families of properties. Vision, for example, enables us to discriminate among colors and olfaction enables us to discriminate among odors.

As is well established, psychophysics can chart what a creature is able to perceptually distinguish via each modality into what are known as quality spaces (see, e.g., Quine, 1960, p. 83ff; Shoemaker, 1982, p. $361 \mathrm{ff}$; Kuehni, 2010). A quality space reflects the perceived similarities and differences between properties within a given family of perceptible properties that a creature can distinguish with a particular sensory modality. Since red is discriminated via vision to be more similar to orange than it is to green, the quality space of colors captures these facts by locating red closer to orange than to green. Since lemons are discriminated via smell to be more like limes than like chocolate, the odor of lemons will be located closer to the odor of limes than to the odor of chocolate in the quality space of odors. These are potentially multidimensional spaces. The quality space of colors, for example, is typically thought to be ordered along the three dimensions of hue, saturation, and brightness (see, e.g., Hardin, 1993); the quality space of sounds involve the dimensions of pitch, timbre, and loudness; and the quality space of odors arguably has many more than three dimensions (e.g., Young, Keller, and Rosenthal, 2014, p. 6).

To be clear, Quality-Space Theory assumes a suitably operationalized behavioral characterization of discrimination that can be experimentally measured, a notion that can be explicated in physical, nonmental terms. But, as Rosenthal emphasizes, the theory is neutral about how to operationalize it - that is a task for experimental psychology. We might, for example, present creatures with successive pairs of stimuli such as color chips to determine whether there are socalled just noticeable differences between the chips or simply examine whether or not creatures are able to distinguish them (e.g., Rosenthal, 2005, p. 201, fn. 56). However they are determined, such quality 
spaces are representations of creatures' perceptual discriminatory capacities — that is, their abilities or dispositions to behaviorally discriminate perceptible properties. ${ }^{6}$

The central claim of Quality-Space Theory is that, in order for a creature to engage in the kind of distinctive discriminatory behaviors captured by its quality spaces, it must be able to be in psychological states that vary in ways that mirror the ways in which the perceptible properties relate to one another. That is, since perceptual states are those mental states that enable creatures to discriminate perceptible properties, we as cognitive scientists posit matching spaces of perceptual states to explain those spaces of perceptible properties. Rosenthal writes,

To discriminate among perceptible properties, a creature must be able to be in states that differ at least as finely as the perceptible properties being discriminated.... The differences among the states in virtue of which the creature can perform these discriminations must reflect the differences among perceptible properties that the creature can discern. So the quality space that reflects the perceptible properties a creature can discriminate by a particular sense modality will also determine the perceptual states that make such discriminations possible (2010, p. 377).

To explain the quality space of colors in which red is closer to orange than to green, we posit that matching space of perceptual states, in which a perceptual state, $\mathrm{R}$, is closer to a perceptual state, $\mathrm{O}$, than to a perceptual state, G. Such spaces of perceptual states match their corresponding quality

\footnotetext{
${ }^{6}$ I note that there are many kinds of color spaces, such as the Swedish Natural Color System and the Munsell Color System, which order the colors along different dimensions and are generated to serve different theoretical purposes (for an overview, see, e.g., Hardin, 1993; Kuehni, 2010). The relevant color space for the theory, however, is the space of colors as they are visually discriminated by creatures. I return to this issue in section 4.2.
} 
spaces of perceptible properties insofar as they are simply extrapolated from them to explain them. ${ }^{7}$ The quality space of colors in that way determines the ordering of the corresponding space of color perceptual states: Each state in a space of perceptual states corresponds to property in the space of perceptible properties - for example, perceptual state R corresponds to the color red — and there is a mapping from the former space to the latter space that preserves the structural relations that hold between the respective properties. ${ }^{8}$

Each quality space of perceptible properties that has been mapped to date is asymmetricaland so each perceptible property occupies a unique location within its space. As a result, perceptual states likewise occupy unique locations within their respective spaces. Such spaces of perceptual states thus holistically identify and individuate some of their properties. Which properties? Again, such spaces of perceptual states are posited to explain a creature's perceptual discriminatory behaviors_-and perhaps the most natural explanation of how perceptual states enable such behaviors is that they represent their corresponding perceptible properties. After all, cognitive science regularly posits mental representations to explain many kinds of behavioral engagements with the

\footnotetext{
${ }^{7}$ This claim should not to be interpreted epistemically: that the space of colors merely provides good evidence for the corresponding space of perceptual states. Rather, it is to be understood metaphysically. Just as we posit electrons to explain perceived paths in gas chambers — and so features of those paths constrain features of electrons—we posit spaces of perceptual states to explain spaces of perceptible properties; so features of the latter determine features of the former. 8 These kinds of spaces are, though related, plainly different. The quality space of colors is a space of properties of external three-dimensional objects in the world; the matching spaces of perceptual states are spaces of internal mental items — states of three-dimensional objects (i.e. persons or brains). While the dimensions that characterize the quality space of colors may include properties such as hue or brightness, the dimensions that characterize the matching space of perceptual states are not those properties, but rather inner analogues of them-what we might call 'hue*' and 'brightness*'.
} 
world. Thus, as I've (2015, p. 452) argued elsewhere, it is reasonable to construe Rosenthal's view as a holistic theory of perceptual content, which I call 'Quality-Space Semantics' ('QSS'):

Quality-Space Semantics: Perceptual state S represents a perceptible property P of type T iff $\mathrm{S}$ occupies a location within the space of perceptual states extrapolated from the space of T-type perceptible properties that corresponds to the location of $\mathrm{P}$ within the space of Ttype perceptible properties.

According to QSS, a perceptual state represents the color red-and not green, blue, something else altogether, or nothing at all-because that state occupies a location within the space of color perceptual states that corresponds to the relative location occupied by red within the quality space of colors. Since a perceptual state represents the perceptible property to which it corresponds, QSS holds that perceptual state's content is accurate only if its corresponding property is present and inaccurate otherwise. ${ }^{10}$

The idea that perceptual content is individuated holistically may immediately strike one as implausible. As Jesse Prinz (2012, p. 132) has recently argued, Rosenthal's view may seem questionable because we can perceive a single color at a time-when one sees a so-called gan zfeld.

\footnotetext{
${ }^{9}$ I note that Rosenthal is drawn to the traditional view of perception, tracing back at least to Thomas Reid (1764/1997), that perceptual states involve not only nonconceptual sensory or qualitative features, but also some conceptualization of what is perceived (see also, e.g., Sellars, 1963; Berger, 2015). If this view is attractive, then, as I've argued in my (2015), QSS is restricted to the nonconceptual sensory components (and uses of 'perceptual state' and related expressions throughout refer not to those states tout court, but to these components).

10 The presence of the relevant perceptible property is a necessary, but perhaps not sufficient, condition for the accuracy of a state because other conditions arguably need to be met. For example, it may be that the property must also be the right kind of cause of the state to rule out cases of verdical ballucination (cf. Grice, 1961).
} 
But to be clear, these spaces of perceptual states are not themselves represented in the mind. Like their corresponding spaces of perceptible properties, spaces of perceptual states are maps or representations of a creature's capacity to engage in a range of perceptual discriminatory behaviors. Thus the relations that determine perceptual states' contents are not relations between occurrent states, but between states a creature is disposed to be in. Thus each perceptual state exhibits a location within a space, whether or not a creature is currently in that or any other state.

Crucially, Rosenthal proposes Quality-Space Theory as an account of qualitative character.

Rosenthal, like many representationalists, rejects the reasons to think that the qualitative character of perceptual experiences is nonrepresentational and irreducible. ${ }^{11}$ Instead, he observes that common sense has it that qualitative states play a role in explaining perceptual discriminations_-and thus urges that the relevant spaces of perceptual states individuate their qualitative characters. He writes,

$[\mathrm{I} f$ mental qualities play a role in perceiving, it's natural to identify them with the properties in virtue of which perceptual states differ. The quality space that captures the similarities and differences among the perceptible properties a creature can discriminate will also describe the mental qualities that figure in such discrimination. And this gives us an account of mental qualities in terms of the quality space that describes a creature's ability to discriminate (2010, p. 377; cf. Sellars, 1956/1997, p. 112; Shoemaker, 1994, p. 305).

Rosenthal is, however, clear that mental qualities are representational in nature (e.g., 2005, p. 208; 2012, p. 24). And on the assumption that representationalism is independently attractive, it is

\footnotetext{
${ }^{11}$ Rosenthal (2010) rejects, for example, the argument that qualitative character is nonrepresentational and irreducible because undetectable quality inversion is possible, arguing that such inversion is in fact impossible (see also, e.g., Tye, 2000).
} 
therefore reasonable to read him as identifying a state's qualitative character with the property of representing a particular perceptible property. In other words, Rosenthal's view can be interpreted as a holistic version of representationalism, which invokes QSS as its theory of content. ${ }^{12}$

As noted, perceptual states can occur both consciously and not—and Rosenthal is clear that what he calls 'mental qualities' can and do occur outside of consciousness. If this terminological choice strikes one as unacceptable, it is perhaps easier to read the view as holding that perceptual contents can occur without being conscious, but that when a perceptual state with a given content is conscious (however that is explained), its conscious character is determined by that state's unique location within a space of perceptual states. For example, a perceptual experience represents the color red — and thereby has a reddish qualitative character — just in case (a) the state is conscious and (b) it occupies a unique location in the space of perceptual states that matches the location of red within the quality space of colors.

\subsection{QSS and Mainstream Theories of Content Compared}

How does QSS compare to other mainstream theories of content? At its most basic, QSS is quite unlike atomistic theories insofar as it holistically individuates contents in terms of perceptual states' relations to one another. In that way, QSS echoes holistic theories of conceptual content such as CRS. But QSS nonetheless differs from most other widely held accounts of content, including CRS. According to QSS, perceptual states' contents are not determined by inferential relations to one

\footnotetext{
12 Rosenthal seems to deny this reading of his view in places (e.g., 2005, p. 223). But he is explicit that he does not endorse a version of representationalism wherein qualitative character depends on conceptual content-and, as we shall see, this is not a commitment of the view as I characterize it. Clark, who defends an account much like Rosenthal's, acknowledges that it can be read as a form of representationalism (e.g., 2004, pp. 571-572).
} 
another, but rather by relations of resemblance and difference, as determined by the resemblance-anddifference relations that characterize their corresponding spaces of perceptible properties.

Like standard atomistic theories of the sort defended by Dretske and Tye, however, QSS is a theory of nonconceptual content. Although there is debate about how to understand the notion, the socalled state interpretation holds that a mental state has nonconceptual content insofar as one need not possess the concepts that characterize its content (see, e.g., Byrne, 2005, p. 233). The contents individuated by QSS are nonconceptual in this way. The (spaces of) perceptual states posited by QSS are at least partially innate, although learning or other processes may adjust them. Spaces of states capture a creature's capacity to discriminate among perceptible properties; without such states, it is unclear how creatures could distinguish stimuli using their sense modalities and interact intelligently with their environments (for an argument to this effect, see Quine, 1969, p. 123). On the plausible empiricist assumption that concepts are learned on the basis of perception, it thus seems that creatures need not possess the concepts that characterize perceptual contents.

Moreover, like standard tracking theories, QSS provides a naturalistic theory of perceptual content. What determines the contents of a creature's perceptual states are the creature's perceptual discriminatory capacities, which can be explained in nonrepresentational, physical terms. QSS is consistent with a broadly functionalist account of mental states, wherein perceptual states are tokenidentified with the inner physical realizers (e.g., in the human case, brain states) of creature's perceptual discriminatory behaviors. And, as I explain shortly, QSS is compatible with perceptual states' representing perceptible properties that are describable physically as well.

A holistic representationalism that depends on QSS has additional advantages. As Rosenthal proposes, the theory explains not only perceptual experiences of external proper sensibles such as color and odor, but also arguably experiences of external common sensibles such as shape and location and bodily sensations such as pains and itches (see, e.g., Rosenthal, 2010, p. 377-378). Of 
course, more can be said about the nature of the contents posited by QSS (for more detail, see, e.g., Rosenthal, 2012, p. 24; Berger, 2015), but this outline should suffice for present purposes. Likewise, the account doubtless faces many prima-facie objections (see, e.g., Prinz, 2012, p. 132; for replies to many objections, see, e.g., Rosenthal, 2005, chapter 7) —and I will return to some of these in section 5. For now, however, I want to offer two new arguments for holistic representationalism.

\section{Arguments for Holistic Representationalism}

In what follows, I will explore two of Pautz's recent criticisms of tracking representationalism, which he claims motivate primitivism about perceptual content. I argue that these considerations instead highlight the virtues of a QSS-based holistic representationalism. ${ }^{13}$

\subsection{The Internal-Dependence Argument}

Pautz (2006; 2010, section 2; 2014, section 18.3) offers a theoretical argument against tracking representationalism, which he dubs the 'Internal-Dependence' Argument. This argument relies on consideration of what he calls 'hypothetical coincidental-variation cases' (2010, p. 340), which involve two individuals whose perceptual states stand in the same tracking relation to a particular perceptible property, but whose discriminatory behaviors differ because of differences in their neural processing of the information about the property. Consider Pautz's (2006, pp. 214ff) example involving Maxwell and Twin Maxwell. ${ }^{14}$ Maxwell is a normal human on Earth. Twin Maxwell lives

\footnotetext{
13 There are of course other kinds of objections to representationalism in general and tracking representationalism in particular (for an overview, see, e.g., Bourget and Mendelovici, 2014), but I do not explore them here because they may not clearly bear on the debate over atomistic/holistic varieties of the view.

14 Some of the details of Pautz's example have been modified for simplicity.
} 
on a planet like Earth, but its alternative environment caused his brain to evolve and develop differently than Maxwell's.

Suppose that Maxwell and Twin Maxwell visually experience an object that exhibits some physically characterized SSR, P, which we ordinarily regard as being in the red range. And suppose that both Maxwell and Twin Maxwell's experiences stand in the same tracking relation to $\mathrm{P}$ whatever content-determining relation the tracking representationalist posits. Maxwell engages in ordinary perceptual discriminatory behaviors such as sorting tokens of $\mathrm{P}$ into groups indicating that they are more similar to color chips that we ordinarily regard as orange than they are to chips that we regard as green. Due to Twin Maxwell's alternative processing of stimuli, when he experiences P, he engages in different discriminatory behaviors: Sorting tokens of $\mathrm{P}$ as being more similar to the chips ordinarily regarded as green than they are to the chips ordinarily regarded as orange.

Pautz maintains that a neutral description of the case generates the reaction that Maxwell and Twin Maxwell have qualitatively distinct color experiences. According to representationalism, this requires that the twins visually represent distinct color properties. But, by hypothesis, tracking representationalism holds that individuals in coincidental-variation cases must experience the same thing because their perceptual states stand in the same tracking relation to the same perceptible property. Pautz concludes that tracking representationalism is false because qualitative character seems internally dependent - related to the internal states of a creature that determine its discriminatory behavior-and not tied to a creature's external relations to perceptible properties.

Rather than rejecting representationalism outright, however, Pautz proposes that perceptual representation, and hence qualitative character, is primitive: A perceptual experience's representing a perceptible property, and thereby having a certain character, is a brute fact about that state which cannot be reductively explained. Indeed, Pautz's anti-reductionism goes one step further, holding 
that perceptible properties themselves are only notional - they are mere representata that are never actually instantiated.

Tracking representationalists have offered varied responses to Pautz's case and Pautz has in turn offered replies (see respectively, e.g., Byrne and Tye, 2006; Pautz, 2014). Tracking representationalists can argue, for example, that Twin Maxwell does not in fact stand in the relevant content-determining relation to P. After all, tracking theories such as Tye's are often glossed in terms of optimal conditions, primarily to explain cases of misrepresentation. Presuming colors exist mind-independently, it would seem that one can represent red even if red is not present (as in hallucination) or fail to represent red even if red is present and the cause of one's perceptual state (as in red-green colorblindness). Tye maintains that misrepresentation occurs when conditions are not optimal, wherein optimality is unpacked in terms of biological functions determined by natural selection or some similar process (e.g., Cutter and Tye, 2011, p. 91). So it might seem open that Twin Maxwell is not in optimal conditions, which thereby explains why he does not experience the same property as Maxwell.

But Pautz urges that we can stipulate that Twin Maxwell's evolutionary history renders him a normal perceiver in his alternative environment, possessing a visual system with the biological function to detect (or otherwise stand in the relevant tracking relation to) $\mathrm{P}$ and that conditions are optimal. That is, whatever naturalistic relation the tracking representationalist proposes, it would seem that a coincidental-variation case can be formulated—suggesting that tracking theories are unworkable.

One might nonetheless protest that appeals to coincidental-variation cases amount to intuition mongering. We might, after all, simply deny our immediate reaction that Twin Maxwell has an experience that is qualitatively distinct from Maxwell's. But rejecting this assumption misses, I think, a crucial theoretical point: Our ordinary folk-psychological attributions of perceptual content 
are sensitive to a creature's complex functional capacities to discriminate among perceptible properties. ${ }^{15}$ The fact that Maxwell and Twin Maxwell track P in the same way is irrelevant to whether they experience $\mathrm{P}$ in the same way (in the eyes of folk psychology). What is relevant is how each perceptually discriminates P from other perceptible properties.

Pautz's primitivist representationalism follows, however, only if we make the abductive assumption that it is the best explanation of Pautz's case. This additional premise is, however, questionable. The fact that our attributions of perceptual content have to do with discriminationdiscerning one perceptible property from others-is instead best explained by the fact that perceptual content is determined holistically, as QSS holds. The fact that P occupies distinct locations in Maxwell and Twin Maxwell's respective spaces is sufficient to show, by QSS's lights, that the twins have distinct experiences. ${ }^{16}$

QSS respects our commonsense reaction to Pautz's case in a way that tracking theories cannot because it takes as its starting point creatures' perceptual discriminatory behaviors. Consider by analogy the debate between atomistic accounts of conceptual content and holistic accounts such as CRS. Although everyone agrees that beliefs stand in inferential connections to one another, atomists take as basic the connection between an individual belief and some aspect of the world and must thus supplement their theory with an independent explanation of inference. Holistic theories such as CRS, by contrast, take as foundational the inferential connections that hold between beliefs and explain conceptual content in terms of those connections. QSS likewise takes the perceived

\footnotetext{
${ }^{15}$ I thank Jake Quilty-Dunn (personal communication) for clarifying this point for me.

${ }^{16}$ How to characterize their contents, however, is an issue to which I return in section 5.2.
} 
connections between perceptible properties — the way in which those properties are discriminated in relation to one another-as the fundamental explananda of a theory of perceptual content. ${ }^{17}$

Reflection on coincidental-variation cases thus provides abductive support for holistic representationalism. The view not only accommodates the deliverances of folk psychology better than tracking representationalism, ${ }^{18}$ but also explains qualitative character naturalistically and is in that way preferable to Pautz's nonreductive alternative.

\subsection{The Structure Argument}

Pautz (2010, section 3; 2014, section 18.2) offers a second experimentally driven argument, which he calls the 'Structure Argument'. In essence, the argument holds that perceptible properties do not vary with perceptual experiences in the way that one would expect if tracking representationalism were true. Pautz claims that many structure judgments seem to be correct: claims such as that a particular sound experience is twice as loud as another or that a particular taste experience is quite like another. But, Pautz observes, experimental evidence shows that doubling a sound wave's amplitude does not actually double its experienced intensity; likewise, two flavors can be experienced to be quite different even though they exhibit very similar molecular structures, or can be experienced to be quite similar despite being molecularly quite different. As Pautz puts it,

\footnotetext{
${ }_{17}^{17}$ Other theorists seem to be converging on the idea that perceptual experience is fundamentally to be explained in terms of discrimination; see, e.g., Schellenberg (forthcoming).

18 Why do our ordinary practices of attributing perceptual content matter? When studying the underlying nature of a feature of the commonsense world — when attempting to reconcile what Sellars (1963, chapter 1) called 'the manifest image' with 'the scientific image'—we must have a commonsense grip on that feature to begin to theorize about it. Without such an understanding, it is unclear what or how to theorize in the first place. Of course, once we have that understanding, we may depart from common sense as we theorize, though such departures should be minimized if possible.
} 
'psychophysics reveals that, even under optimal conditions, there is an extremely bad correlation between phenomenology and the physical property tracked' (2010, p. 337). This seems to pose a problem because tracking representationalism seems to require that manipulating the physical parameters of a perceptible property would give rise to comparable structural changes in the characters of experiences of them; thus either our structure judgments or tracking representationalism is false.

As was the case with the Internal-Dependence Argument, there are various ways in which tracking representationalists might and have replied to Pautz's Structure Argument—and Pautz himself has many rejoinders (for review, see, e.g., Pautz, 2014). But for present purposes I grant that the Structure Argument is plausibly a problem for tracking representationalism.

What I argue is that, properly understood, the Structure Argument instead seems to motivate holistic representationalism. As was the case with Pautz's first argument, primitivist representationalism follows only if we assume that it is the best explanation of the truth of our structure judgments. But, again, this assumption is questionable. To see why, it is necessary to understand how QSS characterizes perceptible properties. To be clear: QSS is not a theory of perceptible properties; it is a theory of the contents of perceptual states. But QSS recommends, and fits nicely with, a promising account of perceptible properties that enables us to explain structure judgments better than primitivism.

What the Structure Argument brings out about tracking representationalism is that the view assumes problematically that only something about perceptible properties as they are merely physically described could explain why we experience them as relating to one another as they do. But since QSS posits perceptual contents to explain creatures' discriminatory behaviors, it does not assume that anything about how those perceptible properties are physically understood independent of those discriminatory behaviors would explain why perceptible properties occupy their respective locations 
in quality spaces. And this must be the case because, as even many color physicalists have observed, we often group physically disparate properties under the same color categories, as in the case of metamers_SSRs that are visually indistinguishable under given illumination conditions, and yet have different wavelength properties. Some have argued that the mere existence of metameric pairs undermines color physicalism (e.g., Hardin, 1993, pp. 63-64; for a reply, see, e.g., Byrne and Hilbert, 2003).

QSS holds that if a creature cannot visually distinguish physically distinct SSRs, those SSRs will be located at the same location in that creature's color space. Hence the dimensions that characterize the relevant quality spaces need not be the dimensions that color scientists or metaphysicians might posit. Rather, they are the dimensions that perceptual psychologists identify in order to classify how perceptible properties vary as they are perceptually discriminated.

In other words, rather than adopting color physicalism, QSS recommends a kind of functionalism about perceptible properties, wherein each perceptible property is type identified with a location within a quality space (see, e.g., Rosenthal, 2001, p. 87; for a related kind of color functionalism, see, e.g., McLaughlin, 2003). This is not to say that perceptible properties are not describable in wholly physical terms. As some color physicalists urge, colors need be anthropocentric only insofar a creature's visual capacities play a role in fixing the reference of our color categories; such properties can still be mind independent and construable in physical terms (see, e.g., Ross, 2010). Most color physicalists, for example, identify colors with the SSRs of objects that stimulate equivalent ratios of retinal activations in normal human beings under standard viewing conditions (see, e.g., Tye, 2000, p. 161; Byrne and Hilbert, 2003, p. 53). On the kind of perceptibleproperty functionalism advocated here, by contrast, each perceptible property is token identical with an equivalence class of physical properties occupying a particular location within a particular creature's space. In the case of colors, these properties will likely be sets of SSRs. Thus, as Rosenthal 
(2005, pp. 168-169) proposes, the view holds that there is a one-to-one mapping of perceptual states to perceptible properties, when those perceptible properties are construed functionally as equivalence classes, and a one-to-many mapping of perceptual experiences to perceptible properties when the latter are construed as the individual physical properties that realize those functional roles.

Holistic representationalism paired with this kind of perceptible-property functionalism thereby predicts and explains how some structure judgments can be true. The combination of views does not require that doubling a sound's experienced intensity involve doubling its amplitude; it requires only increasing the amplitude such that the sound occupies a location in the quality space of sounds that doubles the intensity of the sound along its loudness dimension.

I acknowledge, however, that are many theories of perceptible properties currently available (for review, see, e.g., the essays in Byrne and Hilbert 1997)—and I can neither challenge all plausible alternatives, nor defend this sort of perceptible-property functionalism from plausible possible objections. But for now I note that holistic representationalism paired with property functionalism is attractive insofar as (a) it is naturalistic, unlike Pautz's primitivist representationalism, (b) it respects our structure judgments in a way that tracking representationalism cannot, and (c) its anthropocentric account of perceptible properties is no more problematic on that score than standard varieties of physicalism or primitivism.

\section{Objections}

Though there are many objections that might be leveled at this kind of view, in what follows I focus on two worries that arise out of holistic representationalism's responses to Pautz's arguments.

\subsection{Identical Perceptual Contents?}


Holistic representationalism agrees with Pautz's primitivism that Maxwell and Twin Maxwell have distinct qualitative experiences when they both perceive P. But does it allow that they can have any experiences in common? Prinz (2012, p. 132) has argued that it does not, and that we should therefore reject the view. Since it is unlikely that two creatures have identical perceptual discriminatory capacities and so identical quality spaces, it would seem that the view entails that no two individuals can have identical experiences_-which seems absurd. Tracking and primitivist representationalisms, by contrast, easily explain shared perceptual content in terms of sameness of tracking relation or sameness of primitive representation.

This worry mirrors a familiar challenge to holistic theories of conceptual content such as CRS. Critics such as Jerry Fodor and Ernest Lepore (1992, pp. 17-22) argue that insofar as no two individuals draw precisely the same sets of inferences, it would follow on CRS that no two individuals can have thoughts with precisely the same contents. But if so, then it is unclear how meaningful communication takes place. Many thereby conclude that conceptual content must be atomistic.

Whatever the strength of this critique of CRS, however, the analogous objection to QSS is readily answered. While QSS does hold that it is unlikely that two creatures ever have identical perceptual contents, it nonetheless accommodates a rigorous notion of sufficient similarity of content. ${ }^{19}$ In the mathematical field of topology, there is a procedure for constructing homeomorphisms, continuous functions that map two geometrical spaces onto one another while maintaining the topological features of both spaces. We can use a suitable version of this space-fitting process to compare a given individual's space to another individual's space, identifying certain nodes or regions of their respective spaces as relatively similar points or regions. Insofar as the spaces of two

\footnotetext{
${ }^{19}$ My reply to this objection thus echoes Churchland's (1988) reply to Fodor and Lepore's critique of holism about conceptual content — that such a view can accommodate a notion of sufficient conceptual similarity.
} 
individuals are roughly similar, the representational differences between them will not be meaningful for practical purposes. Indeed, common sense does not attribute divergent perceptual contents except in cases of radical divergence from the norm such as colorblindness. This is not to say that subtle divergences are undetectable. But such deviations are rarely relevant to explaining a creature's capacity to navigate its environment.

\subsection{QSS and Misrepresentation}

But lurking behind Pautz's case is another worry that might seem to undermine holistic representationalism: That there is no reason to regard either Maxwell or Twin Maxwell as inaccurately perceptually representing P. On the assumption that perceptible properties are actually instantiated, a natural reaction to Pautz's case would be to hold that Maxwell accurately represents P-he has an experience of red—whereas Twin Maxwell misrepresents it - he has an experience of green. That is, Twin Maxwell exhibits a kind of colorblindness. But Pautz stipulates that both Maxwell and Twin Maxwell are normal perceivers, which suggests that neither misrepresents P. So how to account for Twin Maxwell's error?

The answer depends on distinguishing two ways to assess the accuracy of perceptual representations, which in turn depends on two ways that perceptible-property functionalism allows us to taxonomize perceptible properties. Since QSS holds that a perceptual state's content is accurate only if its corresponding property is present, there is a way in which perceptible properties, and hence the accuracy of a perceptual state, can be indexed relative to an individual's particular quality space. That is, we can regard a perceptible property as being functionally realized simply by whatever property (or set of properties) occupies a location within an individual's quality space. Suppose Twin Maxwell's individual color space places P at location L2. On this view, Twin Maxwell accurately represents P only if he is in a state that corresponds to location L2 in his space of perceptual states 
(indexed in an individual-relative way). It is in this individual-relative manner that neither Maxwell nor Twin Maxwell misrepresent P.

But folk psychology has it that ordinary perceivers can see the same colors. And we can account for this fact by distinguishing another way to taxonomize perceptible properties, one that involves reference to standard spaces. The reason why it would be natural to regard Twin Maxwell as misrepresenting $\mathrm{P}$ is that $\mathrm{P}$ occupies the red location within the standard color space for ordinary buman perceivers, but occupies the green location within his color space. A standard space is a space generated by a process such as averaging over the discriminatory abilities of individuals within a relevant group. The standard color space for ordinary human perceivers is arguably an average of the color spaces of normal adult human beings — or perhaps the space that reflects the maximal number of colors discriminable by normal adult human beings. ${ }^{20}$ However it is that such standards are determined, it is the case that for each type of individual and for each type of perceptible property discriminable by those individuals by a particular modality, there is a space that is standard for those individuals. And this allows us to taxonomize perceptible properties in a standard-relative way, wherein each perceptible property is functionally realized by the property (or set of properties) that occupies a location within the relevant standard space. ${ }^{21} \mathrm{P}$ therefore occupies a location in Twin

\footnotetext{
${ }^{20}$ If the process involves averaging, we can generate such composite spaces via the mathematical procedure of multidimensional scaling, enabling data from many subjects to be scaled to capture the relative similarity-and-difference measures of the cohort (for discussion, see, e.g., Clark, 1993, pp. 100-101).

${ }^{21}$ Other theorists have been converging on the idea that there are distinct ways to taxonomize perceptible properties. Jonathan Cohen (2009), for example, defends a version of color relationalism, according to which colors are relational properties of the form object $O$ is color $C$ for perceiver $P$ under viewing conditions $V$. On this view, objects exhibit countless colors, and creatures can accurately experience those colors in different viewing conditions. To accommodate visual misrepresentation, then, Cohen (2009, p. 128ff) claims that we can taxonomize colors in two ways: In a fine-grained way, relative to individuals in particular circumstances, and in a coarse-grained way, relative to groups in particular circumstances.
} 
Maxwell's color space that matches the location of the green SSRs in the standard human color space.

The decision to judge Twin Maxwell's perceptual experience as accurately representing a property taxonomized in a standard-relative way depends on whether or not we regard him as being a member of the group generating the standard against which his state is judged. There may be theoretical reasons not to include him in the group of normal human beings, such as biological criteria regarding species individuation. Such decisions may also have a practical dimension. If Twin Maxwell lived on Earth, we would likely hold that he is a member of our species, who, because of differences in the development of his brain, systematically misrepresents $\mathrm{P}$, which is red, as green. ${ }^{22}$

But since Twin Maxwell is stipulated to be a normal member of an alien species, we might hold that he accurately experiences SSRs relative to a standard space that captures his species' spaces of SSRs. But in that case, the standard space of SSRs for Twin Maxwell's species cannot be the color space determined by ordinary human beings. We must instead regard that group of properties as another kind of property, which, because of their functional similarities to the colors, we might call the colors + . It is of course possible that the same SSR, P, might both functionally realize a color (e.g.,

And creatures can plainly misperceive these coarse-grained colors. Like Cohen's view, QSS can taxonomize perceptual contents both relative to individual's own spaces of perceptible properties and relative to standard spaces. Moreover, QSS similarly holds that the boundaries for standard-relative spaces are fluid and determined contextually. But QSS has an advantage over Cohen's view insofar as it does not hold that a creature invariably accurately represents perceptible properties indexed in an individual-relative way.

22 There is thus a way in which, like standard Dretske-Tye theories, holistic representationalism holds that perceptual content, and thus qualitative character, is externalist. Insofar as the decision to judge a state as accurate in part depends on whether or not the state corresponds to a property taxonomized relative to creatures of a given kind, it depends on factors beyond the creature's internal constitution. But determining whether or not a creature accurately represents a property in an individual-relative way is an internalist matter. 
red) in our color system and a color+ (e.g., blue+) in Twin Maxwell's species' space of colors + . Thus, when discriminating P, Twin Maxwell might accurately represent blue+, whereas he misrepresents green. From the perspective of QSS, it is not clear what hangs on the decision to regard his perceptual experience as accurate or inaccurate from these standard-relative perspectives. ${ }^{23}$ Either way, QSS can explain the representational differences between Maxwell and Twin Maxwell.

\section{Conclusions}

Representationalism is appealing. But most versions depend on atomistic tracking theories of perceptual content - and are thereby problematic. There are, however, good reasons to think that perceptual experience is instead a holistic affair. I have developed and defended here a version of representationalism that depends on the holistic theory of perceptual content that I have called 'QSS'. I have not decisively shown that tracking or primitivist versions of representationalism are false and I have not exhaustively worked out the details of this holistic view. At the very least, however, it should be explored as an exciting alternative to other forms of representationalism.

\footnotetext{
23 Whether or not we wish to assess a creature's perceptual states as accurate in these ways depends on our theoretical purposes. If we want to explain why a creature successfully navigates its environment, it is perhaps more useful to assess their states with regard to perceptible properties understood in individual-specific ways. If we wish to explain whether a creature visually experience the colors 'as they are', we will likely opt for standard-relative judgments. One might balk at the fact that QSS holds that it is unlikely that most creatures accurately perceptually represent the colors understood in a standard-relative way. But we should not be surprised that creatures often slightly misrepresent the world relative to group standards or be alarmed that no creatures experience perceptible properties in precisely the same ways-if anything, we should expect these things (for other examples of ordinary systematic misperception, see, e.g., Mendolovici, 2013; McLaughlin, 2016).
} 
Department of English and Philosophy

Idaho State University

\section{References}

Berger, J. 2015: The sensory content of perceptual experience. Pacific Philosophical Quarterly, 96, 44668.

Block, N. 1986: Advertisement for a semantics for psychology. Midwest Studies in Philosophy, 10, 61578.

Block, N. 1995: On a confusion about a function of consciousness. Behavioral and Brain Sciences, 18, $227-87$.

Bourget, D. and Mendelovici, A. 2014: Tracking representationalism: Lycan, Dretske, and Tye. In A. Bailey (ed.), Philosophy of Mind: The Key Thinkers. Bloomsbury Academic, 209-235.

Brogaard, B. (ed.) 2014: Does Perception Have Content? New York: Oxford University Press.

Byrne, A. 2005: Perception and conceptual content. In M. Steup and E. Sosa (eds.), Contemporary Debates in Epistemology. Malden, MA: Blackwell, 231-50.

Byrne, A. and Hilbert, D. (eds.) 1997: Readings on Color, Volume 1: The Philosophy of Color. Cambridge, MA: MIT Press.

Byrne, A. and Hilbert, D. 2003: Color realism and color science. Behavioral and Brain Sciences 26, 3-64.

Byrne, A. and Tye, M. 2006: Qualia ain't in the head. Nô̂s, 40, 241-55.

Chalmers, D. J. 2010: The Character of Consciousness. Oxford: Oxford University Press.

Churchland, P. 1988: Conceptual similarity across sensory and neural diversity: The Fodor/Lepore challenge answered. The Journal of Philosophy, 95, 5-32. 
Churchland, P. 2007: On the reality (and diversity) of objective colors: How color-qualia space is a map of reflectance profile space. Philosophy of Science, 74, 119-49.

Clark, A. 1993: Sensory Qualities. Oxford: Clarendon Press.

Clark, A. 2000: A Theory of Sentience. Oxford: Oxford University Press.

Clark, A. 2004: Sensing, objects, and awareness: Reply to commentators. Philosophical Psychology 17, $553-79$.

Cohen, J. 2009: The Red and the Real. Oxford: Oxford University Press.

Cutter, B. and Tye, M. 2011: Tracking representationalism and the painfulness of pain. Philosophical Issues, 21, 90-109.

Dretske, F. 1981: Knowledge and the Flow of Information. Cambridge, MA: MIT Press.

Dretske, F. 1995: Naturalizing the Mind. Cambridge, MA: MIT Press.

Fodor, J. 1987: Psychosemantics. Cambridge, MA: MIT Press.

Fodor, J. and Lepore, E. 1992: Holism: A Shoppers Guide. Cambridge, MA: Blackwell.

Grice, H. P. 1961: The causal theory of perception. Proceedings of the Aristotelian Society, 35, 121-52.

Hardin, C. L. 1993: Color for Philosophers: Unweaving the Rainbow (Expanded Edition). Indianapolis: Hackett.

Harman, G. 1987: (Non-solipsistic) conceptual role semantics. In E. Lepore (ed.), New Directions in Semantics. London: Academic Press, 55-81.

Harman, G. 1990: The intrinsic quality of experience. Philosophical Perspectives, 4, 31-52.

Hill, C. 2009: Consciousness. Cambridge, UK: Cambridge University Press.

Kouider, S. and Dehaene, S. 2007: Levels of processing during non-conscious perception: A critical review of visual masking. Philosophical Transactions of the Royal Society B, 362, 857-75.

Kriegel, U. 2009: Subjective Consciousness: A Self-representational Theory. Oxford: Oxford University Press. Kuehni, R. G. 2010: Color spaces and color order systems: A primer. In J. Cohen and M. Matthen 
Holistic Representationalism

(eds.), Color Ontology and Color Science. Cambridge, MA: MIT Press, 3-36.

Lycan, W. 1996: Consciousness and Experience. Cambridge, MA: MIT Press.

McDowell, J. 1994: Mind and World. Cambridge, MA: Harvard University Press.

McLaughlin, B. 2003: The place of color in nature. In R. Mausfield and D. Heyer, (eds.), Colour

Perception: Mind and the Physical World. Oxford: Oxford University Press, 475-502.

McLaughlin, B. 2016: The skewed view from here: Normal geometrical misperception. Philosophical

Topics, 44, 231-99.

Mendelovici, A. 2013: Reliable misrepresentation and tracking theories of mental representation. Philosophical Studies, 165, 421-43.

Neander, K. 2006: Naturalistic theories of reference. In M. Devitt and R. Hanley (eds.), The Blackwell Guide to the Philosophy of Language. Malden, MA: Basil Blackwell, 374-91.

Papineau, D. 1984: Representation and explanation. Philosophy of Science, 51, 550-72.

Pautz, A. 2006: Sensory awareness is not a wide physical relation: An empirical argument against externalist intentionalism. Noûs, 40, 205-40.

Pautz, A. 2010: Do theories of consciousness rest on a mistake? Philosophical Issues, 20, 333-67.

Pautz, A. 2014: The real trouble for phenomenal externalists: New empirical evidence for a brainbased theory of consciousness. In R. Brown (ed.), Consciousness Inside and Out: Phenomenology, Neuroscience, and the Nature of Experience. New York: Springer, 237-98.

Prinz, J. J. 2012: The Conscious Brain: How Attention Engenders Experience. Oxford: Oxford University Press.

Quine, W.V. 1960: Word and Object. Cambridge, MA: Harvard University Press.

Quine, W.V. 1969: Epistemology naturalized. In Ontological Relativity and Other Essays. New York: Columbia University Press, 69-90.

Reid, T. 1764/1997: An Inquiry into the Human Mind on the Principles of Common Sense. D. R. Brookes 
(ed.), University Park, PA: The Pennsylvania State University Press.

Rosenthal, D. M. 1991: The independence of consciousness and sensory quality. Philosophical Issues 1, 15-36.

Rosenthal, D. M. 2001: Color, mental location, and the visual field. Consciousness and Cognition 10, 8593.

Rosenthal, D. M. 2005: Consciousness and Mind. Oxford: Clarendon Press.

Rosenthal, D. M. 2010: How to think about mental qualities. Philosophical Issues 20, 368-93.

Rosenthal, D. M. 2012: Awareness and identification of self. In J. Liu and J. Perry (eds.), Consciousness and the Self: New Essays, Cambridge, UK: Cambridge University Press, 22-50.

Ross, P. 2010: Fitting color into the physical world. Philosophical Psychology, 23, 575-99.

Sellars, W. 1963: Science, Perception, and Reality. London: Routledge and Kegan Paul.

Schellenberg, S. forthcoming. Perceptual consciousness as a mental activity. Nô̂s.

Shoemaker, S. 1982: The inverted spectrum. The Journal of Philosophy, 79, 357-81.

Shoemaker, S. 1994: Self-knowledge and 'inner sense': Lectures I-III, Philosophy and Phenomenological Research, 54, 249-314.

Tye, M. 1995: Ten problems of Consciousness: A Representational Theory of the Phenomenal Mind. Cambridge, MA: MIT Press.

Tye, M. 2000: Consciousness, Color, and Content. Cambridge, MA: MIT Press.

Weiskrantz, L. 1997: Consciousness Lost and Found: A Neuropsychological Exploration. Oxford: Oxford University Press. 